\title{
THE DILEMMAS OF TEXTBOOK SELECTION - THE DEPARTMENT OF EDUCATION'S 2007 SCREENING OF GRADE 12 HISTORY TEXTBOOKS - A CASE STUDY
}

\author{
DOI: http://dx.doi.org/10.17159/2223-0386/2015/n14a2 \\ Rob Siebörger \\ School of Education \\ University of Cape Town \\ Rob.Sieborger@uct.ac.za
}

\section{Abstract}

Textbook selection presents a conundrum for history as a school subject. On one hand it is desirable that the best textbooks are available to be used in classrooms, on the other selection appears to imply control over what can be studied, or even bias and state interference. This is a case study of the textbook screening of Grade 12 history textbooks conducted by the Department of Education in January 2007, in which the author was a participant. It is based upon the criteria and evaluation report forms for the 10 books that were submitted for approval. The article is in three parts: a description of the selection criteria employed by the department and a discussion of the issues that they raise in terms of selected literature on textbook assessment in history; an analysis of the way in which the selection criteria were used in the textbook screening process followed by a discussion of what it concerns; and, in conclusion, a consideration of the place and importance of textbook selection to history education.

Keywords: Textbooks; NCS FET History; Department of Education; Selection; History Education; Criteria.

\section{Context}

There has been textbook selection for South African schools for a considerable length of time. Books have had to be approved by education departments before being permitted to be used in public school classrooms or purchased by them. This is an account of the selection process that operated for Grade 12 textbooks in 2007, discussed as a case study of the development and use of history textbook selection criteria. It is in three parts: a description of the selection criteria employed by the Department of Education and a discussion 
of the issues that they raise in terms of selected literature on textbook assessment in history, an analysis of the way in which the selection criteria were used in the textbook screening process followed by a discussion of what it concerns and, in conclusion, a consideration of the place and importance of textbook selection in history education.

A new South African curriculum for the final three years of schooling, the National Curriculum Statement (NCS) for Further Education and Training (FET), was published in 2003 (Department of Education, 2003). ${ }^{1}$ In creating the curriculum the Department of Education had backtracked significantly on previous policy for Further Education and Training, which had envisaged a "Further Education and Training Certificate" with separate outcomes-based qualifications for each National Qualification Framework level (Grade $10=$ NQF Level 2, Grade $11=$ NQF Level 3 and Grade $12=$ NQF Level 4). Instead, the new NCS strongly resembled the Revised National Curriculum Statement (RNCS) (Department of Education, 2002), the curriculum published the year before for the first nine years of schooling and it was decided that the long-standing Senior Certificate examination would live on in a new format as the National Senior Certificate (NSC), with fewer subjects and similar examination requirements, set nationally, not provincially. The new curriculum was introduced into Grade 10 in 2006, and in the following grades in the succeeding years.

One of the problems facing the Department of Education was that the existing textbooks for the Senior Certificate were (with a few latterly adapted exceptions) written for the former apartheid education departments and used for provincial Senior Certificate examinations. It was apparent that there would need to be "national" textbooks for the new national examination and that these books would need to be approved for use in the country as a whole, not per province. Thus it was that with very little advance preparation and consultation, the Department of Education had to put an approval mechanism into place for Grade 10 books (in the first place), so that they could be available for ordering for schools in 2005. Having then piloted what was referred to as the "textbook screening" of the proposed Grade 10 books, screening for Grade 11 and 12 textbooks followed in consecutive years, with

1 The first school curriculum developed in South Africa post-1994 was the Interim curriculum, from 1996, which altered but did not entirely replace the existing curriculum for Grades 1 to 9. Nated 550, the curriculum for Grades 10-12 continued. In 1998 an entirely new, outcomes-based, curriculum was introduced for Grades 1- 9, known as Curriculum 2005. This was replaced by the Revised National Curriculum Statement (RNCS) curriculum from 2004. The National Curriculum Statement (NCS) for Grades 10-12 was introduced from 2006. These curricula were replaced in their turn by the Curriculum and Assessment Policy Statement (CAPS), Grades R-12, in 2012. 
little change to the procedure that was initiated in 2005.

The process operated broadly as follows. Textbooks' publishers were invited to submit pre-publication copies of their books (a learner book accompanied by a teacher book), which were expected to be in as close to as final a state as possible. Teams of screeners were appointed for each subject, according to the number of books submitted for it. They were departmental officials and subject advisors from the provincial education departments - a strict condition being that they had not written any textbooks for the curriculum, nor were they employed by publishing companies. A week was set aside for the screening. It was left to each team to assign three of its members to screen a book and to allow about a day to process it.

An innovation for 2006 was that a representative from a university was invited to join certain of the teams to strengthen them. I was appointed to the team of History screeners. The following is a description and analysis of the selection criteria that were used in the screening process.

\section{Selection criteria: The criteria used in 2007}

The 2007 screening teams were provided with a set of Guiding Criteria for Selecting Textbooks (Department of Education, 2007). ${ }^{2}$ It comprised four generic sections that were used for all subjects and a specific section (Section 5) for each particular subject.

These were the generic criteria used:

\section{Section 1: CONTENT/CONTEXT}

1.1 The textbook covers all the Learning Outcomes (LOs) and the Assessment Standards (ASs) of the subject.

1.2 The textbook covers the suggested content and this is appropriately sequenced.

1.3 he content is suitably paced and the weighting of LOs is appropriate.

1.4 The content is current and up-to-date.

1.5 The content places learning in context i.e. integrates Assessment Standards within the subject to give learners an authentic learning experience.

1.6 The content is appropriately scaffolded.

1.7 There is clear integration of theory and applied competence.

1.8 The content is sensitive to diversity e.g. culture, religion, gender, etc.

1.9 The textbook provides a variety of meaningful activities for individuals, pairs

2 These are the criteria that were used in 2005 and 2006. I am not aware that they were published publicly, or made available before the 2005 screening, but they were not confidential nor were screeners asked to treat them or the process itself confidentially. 
and groups.

1.10 The level of the content is appropriate for the specific grade.

1.11 The language used and vocabulary are appropriate for the grade and language level.

1.12 Key concepts and terms are clearly defined.

1.13 The language and vocabulary are correct and appropriate for the subject.

\section{Section 2: LEARNING ACTIVITIES \&ASSESSMENT}

1.1 Learning activities and assessment tasks are derived from Learning Outcomes (LOs) and Assessment Standards (ASs).

1.2 The textbook presents the learner with learning and assessment activities appropriate to the subject.

1.3 Assessment tasks are aligned to the Programme of Assessment as described in the Subject Assessment Guidelines (SAG).

1.4 A variety of learning activities and assessment tasks are used.

1.5 Learning and assessment targets learner achievement at different levels of complexity.

1.6 Learning and assessment tasks are clearly formulated and unambiguous.

1.7 Assessment tasks and learning activities provide for daily assessment.

1.8 Learning and assessment tasks allow for expanded opportunities for learners.

1.9 Learning activities and assessment tasks are appropriately scaffolded.

1.10 Assessment activities reflect the integration of Assessment Standards (ASs).

\section{Section 3: LAYOUT, DESIGN AND OVERALL QUALITY}

1.1 The text is structured, using headings and sub-headings.

1.2 The font and typeface are clear and easy to read.

1.3 The illustrations and diagrams are clear and relevant, without bias.

1.4 The paper is of a good quality and bound securely. [If a draft copy/manuscript is submitted a clear indication of this must be given.]

1.5 The textbook has table of contents with clear reference to chapters and page numbers.

\section{Section 4: TEACHER GUIDE}

1.1 Provides clear and systematic guidance on the use of the textbook.

1.2 Provides examples of a work schedule which speaks to the content, sequence and pace of the Learner's Book.

1.3 Includes an exemplar assessment plan for the grade which speaks to the formal assessment tasks in the Learner's Book.

1.4 Provides memoranda, check lists, rubrics, etc. that match the assessment tasks 
in the textbook.

1.5 Provides suggested answers solutions / memoranda / assessment tools for learning activities / exercises.

Some observations assist in gaining a broader understanding of these 26 criteria. For each of the five sections the three evaluators were expected to agree among themselves on a score from a four point scale and to award a "final score" out of four for the book $(1=$ poor or no criteria covered. i.e. the material would require extensive changes to be made to be considered suitable; 2 = Insufficiently covers the criteria; 3 = Good coverage of criteria, with minor shortcomings; 4 = Excellent, fully covers the criteria / suitable for its purpose). While these scores were never quantitatively analysed or used other than as a rough indication that a book should not be approved if it had a final score of less than 3, the scoring system had the effect of treating all the sections equally, whereas they were not equal at all and there was no mechanism for prioritising any of them. The same comment must be made about the individual criteria. "1.4 The content is current and up-to-date" is surely a very much more important criterion than, e.g., "1.7 There is clear integration of theory and applied competence." But the criteria were not scored or aggregated in any way and their chief purpose was to enable the scanners to compile a list of "Strong points" and a list of "Weak points" per book. These two lists and the scoring for each section comprised the entire evaluation and on the basis of them the screeners had to designate the book "Approved", "Conditionally approved" or "Not approved". (The final decision was made by the entire team.)

It is also apparent that there was a particular focus on the technical specifics of the NCS and the broader National Qualification Framework (NQF) (SAQA, 2001). 13 of the 23 generic criteria for Sections 1 and 2 on the content and activities of the textbooks refer directly to the apparatus of the curriculum and, while they are not unimportant aspects (nor objectionable), the cumulative effect of them on the screeners was to reduce their activity in this regard to mechanical checks against the curriculum documents.

The criteria for history were:

5.1 The textbook provides learners with guidance of how to

- Identify, select and access relevant sources of information

- Extract information from sources

- Analyse, interpret and evaluate information and data

- Engage with and analyse historical sources. 
5.2 All sources of illustrations, diagrams, cartoons must be fully acknowledged as the acknowledgement also provides information needed.

5.3 Topics are framed using key questions.

5.4 Organising themes of content are recognisable.

5.5 The volume of content suggested is appropriate for the 4 hours per week allocated to the subject.

These criteria, by any consideration, are very limited. The best one can probably conclude from them is that the books that satisfied all five criteria were compiled with care and some insight. 5.1 and 5.2 appear to have direct relevance to requirements for the Senior Certificate examination (see Department of Education 2005:21). 5.3 refers to the way in which historical content knowledge is presented in the NCS, where a key question frames each of the seven Grade 12 topics (Department of Education 2003:26-27). It is not apparent what 5.4 refers to, nor what it expects (no gloss or explanation of the criteria was provided). The final criterion, on the relation of volume to teaching hours, is extremely subjective in the judgement that it requires and it ignores two dominant examination realities, viz. that the content topics all need to be more or less the same length and that no teacher would try to cover all seven topics in the year (a selection of them would be made according to examination guidelines). But, it is useful that the criteria highlighted source work and aspects of the historical method, based on the four Assessment Statements for Historical Enquiry, which is Learning Outcome 1 of the NCS (Department of Education, 2003:17).

The criteria are next discussed, in terms of literature on history textbook selection.

\section{Selection criteria: Discussion of the criteria for history textbooks}

It is extraordinarily difficult to create comprehensive selection criteria for textbooks that can be administered consistently and used with confidence to determine which books are prescribed. In a review of methods of school textbook research, Jason Nicholls (2003) considered the evaluation of history textbooks. He reviewed the (limited) literature available from a research rather than a selection point of view. Fetsko (1992) is an example of a generic list of selection criteria to which he drew attention, while Stradling (2001), together with Pingel (1999/2010), is his favoured author on history textbook selection (Nicholls, 2003:16-17). 
William Fetsko's categories are useful for comparison with the generic 2007 Guiding Criteria (Department of Education, 2007). His list of categories is: 1. Subject matter (content and skills, together with meeting curriculum requirements); 2 . Community standards (which include values, the treatment - fair or biased - of groups in society and human rights; 3. Readability (including level, prior knowledge, writing comprehension and style); 4. Format (presentation, illustrations, ideas and concepts, activities, the abstract and the familiar) and 5. Quality of the text (size, production quality, etc.). Conspicuously missing from these measures in the Guiding Criteria, are that content is not first in the Department of Education's list; skills are only mentioned very obliquely in assessment standards and tasks; "community standards" do not feature at all and readability has no place beyond language and vocabulary. The format and quality of text, however, are criteria that are adequately dealt with by the Department of Education.

I argued in an unpublished 1996 conference paper (Siebörger, 1996), based largely on the experience of writing textbooks at the time of the introduction of the Interim curriculum (1995-1997), that there ought to be seven general criteria (posed as questions) for textbook selection. They were: 1 . Who is the book written for? (Teachers or learners, first or second language readers?) 2. What method(s) of teaching is the book based on? (Teacher-centred or learner -centred / whole class teaching / group work / individual work /skillsbased?) 3. What is the approach to content of history? (The way the content is presented, and whether up to date?) 4 . What is the approach to outcomes based education and assessment? 5. How easy is it to read the book? (Reading level, historical terms used); 6. What kinds of activities are there? (Tasks for learners, how do they learn and how varied are they?) and 7 . How attractive is the book? (Layout; illustrations; quality). The 2007 Guiding Criteria include numbers 4, 6 and 7 of these, but there are large gaps regarding the other four criteria, especially on the audiences for the books and their needs, and the emphasis on teaching and learning (1,2 and 6), which are missing in Department of Education criteria.

A very early attempt to match selection criteria for history textbooks to an assessment schedule was published in 1970 by Jeanette Coltham, on behalf of a working group which had been tasked to consider the assessment of history books. The group produced a set of 12 criteria and a schedule for assessing them, which, it was believed, "would help any teacher to make a fairly speedy and comparatively objective assessment of a history book; between 15 and 25 
minutes [appear] necessary ...” (Coltham, 1970:214). The criteria were, A. Use of language; B. Special terminology; C. Facts (concrete or generalised); D. Treatment of facts (what was done with them); E. Concern for human beings; F. Views of society; G. Notion of change; H. Cause and effect; I. Time (chronology); J. Illustrations; K. Activities and exercises suggested and L. Format. A model of this kind if used in the 2007 textbook screening would have produced very clear and objective data, such as, a text-illustration ratio, and, for example, the rubric for assessing "G. Notion of change": "Assessment for both ratings is made by skimming through the book to note whether some or all of the following are present: (1) direction in the text to make comparisons; (2) contrasting illustrations are juxtaposed; (3) diagrams are used; (4) a section is devoted to the idea of change. Presence of at least two of these is required for endorsement" (Coltham, 1970:217). In terms of relevance, C, D, E, F, G, H, I are all aspects that were not included in the Guiding Criteria.

Another early attempt to understand the process of the selection of history textbooks, Wilkes (2007), is unique in that it was compiled from the point of view of the author and publisher of a textbook. It draws valuable attention to the constraints involved in producing history textbooks and how they influence the final product. These were characteristics that were not considered at all in the 2007 screening. Had they been, the results would have been far more nuanced and more considerate of the importance of the production process. (Textbook publishers are likely to have approved of the recognition of the practical issues they faced, but would, equally, have been sensitive to the criticisms of their books that would have emerged in the event.) John Wilkes' conditions for "Making the best use of textbooks" were: The constraints within which the textbook author must work; Compression and organisation of material; Oversimplification; The use of textbooks - the publisher' view; The use of textbooks - in schools; Technical and commercial constraints; Omission; and Availability of source material (Wilkes, 2007).

The substantial treatments of textbook selection in history that assist in analysing the Guiding Criteria regarding history books in particular, are those produced by the Sparkling Waters colloquia ${ }^{3}$ in South Africa in 1993

3 Two colloquia on "School History textbooks for a democratic South Africa" were held under the auspices of the Georg-Eckert Institute for International Textbook Research at the Sparkling Waters Conference Centre in Rustenburg in 1993. They were followed by a workshop on School History Textbook Writing in Cape Town in 1995. Collectively these events are often referred to as "Sparkling Waters". The product of the colloquia was a joint statement in three parts: Textbooks and the History Curriculum; What new history textbooks should be like; and The production of textbooks. 
(Siebörger, 1994a, 2006) and that of Robert Stradling (2001), mentioned above. It is a tragedy for history teaching in South Africa that the Sparkling Waters criteria were not considered by the Department of Education for the 2005-2007 textbook screening (or that which took place in 2011) and it is equally regrettable that a thorough set of benchmarks such as Stradling's, which was a project of the Council of Europe, was also not employed.

The Sparkling Waters criteria were the product of extensive discussion by textbook writers and academics, facilitated by the Georg Eckert Institute for International Textbook Research during 1993-1995. They cover virtually all characteristics of history textbook writing and were published under six main headings: 1 Historical consciousness; 2 Language of textbooks; 3 Practical criteria (format and layout, structure and illustration, learning abilities, interactive instruction and independent inquiry; 4 Criteria which stimulate perception and experience in textbooks (emotional and visual perception, multi-dimensional approaches, multi-perspectival approaches); 5 Criteria which stimulate understanding and interpretation (standards of historical discourse, narrative, skills of historical thinking, a dynamic process); and 6 . Criteria reflecting the role of history in present-day life (see fuller discussion in Siebörger, 2006).

Stradling created a checklist of 40 questions organised into three main categories: questions designed to evaluate the content and pedagogy of history textbooks; questions which focus on the intrinsic qualities of textbooks (regardless of the country in which they are published and used, the content covered, or the age and ability of students) and questions which focus on the extrinsic factors (external to the processes of writing and publishing) (2001:257-8). (He paid little attention to how they should be applied, however, stating, "History teachers and committees authorising textbooks will no doubt look at possible textbooks in some depth before deciding which ones are most suitable" (2001:258).) Many of the questions touch on factors that have already been discussed. The following are examples of questions drawn from each of the categories that have not already been mentioned above: "How much emphasis is given to political, diplomatic, economic, social and cultural history within the contents of the textbook?" "Can any patterns be discerned in those topics, events, groups, dimensions and perspectives, which are omitted from the text, illustrations, source material or assessment tasks? Are there any implicit messages in these omissions?" "What prerequisite knowledge, if any, is required for the student to effectively access and use 
this textbook?" "Does the textbook provide opportunities for the student to develop a comparative perspective by, for example, contrasting events or developments in two or more countries or regions?" "Is it likely that this textbook will arouse their interest in the subject and their curiosity about the past?" "Has the book (or parts of it) been field tested or trialled with teachers and students?" Such questions would promote a much deeper analysis than the Guiding Criteria permitted.

There is one conspicuous omission in the whole of the above discussion of textbook selection. It is the matter of who the writers and publishers of the books were? These are key questions in the transformation of education in South Africa, as very plainly identified (together with concomitant dangers of corruption) by Andre Proctor and Mary Monteith, who draw attention to the need to level the playing fields for small publishers (1993:32, 34, 43). Some will be surprised and offended by the absence of any reference to these very significant concerns in the process of the textbook scanning. Others might be relieved that the Department of Education did so little to rock the existing boat, by not drawing attention to this in any way.

While the criteria were crucial to the process, no less crucial was the way in which they were applied by the screening teams.

\section{Applying selection criteria: The 2007 process}

Ten Grade 12 textbooks were submitted for screening by educational publishers in January 2007, one book per publisher in almost all cases. The Evaluation Report Forms that were completed by the screening teams for these books were analysed. In brief, six of the books were awarded a final score of 4 ("Excellent, fully covers the criteria / suitable for its purpose", i.e. awarded a score of 4 for the majority of the five sections), five of which were approved and one conditionally approved (subject to changes being made); three books were awarded a 3 ("Good coverage of criteria, with minor shortcomings") all conditionally approved and one was awarded a 2 ("Insufficiently covers the criteria”) and not approved.

In terms of the data contained in the "Strong Points" and "Weak Points" columns, there were 93 strong points and 102 weak points listed in all - very similar numbers, an average of 20 per book. All except one of the books that had been awarded a 4 had more positive comments than negative ones. The other four books had more negative than positive comments, which is what 
one would probably expect, but as the comments carried no weighting there is no necessary reason for this to be so. There is no perceptible difference in the numbers of comments recorded by the various groups of screeners. An improvement would have been to have weighted the sections, e.g. with the History section the most important, followed by the other three in their respective order (e.g. History possibly 40\%, Content/context 25\%, Learning activities and assessment 15\%, Layout and design $10 \%$ and Teacher guide $10 \%)$.

An analysis was made of the comments recorded in the two columns of each report. It excluded the learning activities and the teacher guides, as both were very mechanistic evaluations and did not contribute many comments. There were also few points made about the layout, design and overall quality, nine in all - two on the structure of the text, two on the font and type, and five (all negative) on the quality and choice of the illustrations.

It is not possible to categorise all the comments made. Some fell outside the ambit of Guiding Criteria, such as "Chapter summaries and integration with other subjects are commendable;" "Warning statement needed to the effect that the requirements for the examination are subject to further change;" "Interesting 'Did you know?' and 'Extension Activity' sections", "The rich bibliography attests to the good quality of the book" and "Practice exam papers are provided as exercises for learners." Of the comments made relating to Section 1 Content/Context, by far the most were made regarding the "suggested content" (1.2). Fewer than half as many were made about language, vocabulary and concepts, while a number concerned the Learning Outcomes and Assessment Standards. There were not many other comments on Section 1.

The range of comments on content issues included praise, criticism and suggestion, as the following excerpts illustrate:

- Different interpretations are provided and this allows for objectivity in the handling of issues, e.g. Cold War;

- Concise coverage of the NCS content in the intended sequence (with Heritage the exception);" "No explanation is given for the change of curriculum sequence in Chapters 4 and 5. The Teacher's Book (p.x) anticipates the opposite. Chapter 4 begins (p.xxx), 'The collapse of apartheid in South Africa came as a surprise to many people.' This is the reason why the curriculum puts the collapse of the USSR first and it is suggested that the authors should either explain why they ignored this sequence or restore the curriculum order in the book; 
- $\quad$ Content needs to be expanded in the following areas: role of China in the Cold War; civil society protests in Eastern Europe, SA involvement in the Angolan war; National symbols in Heritage;

- Content on pp. xx-xx irrelevant to content framework and can be collapsed as a brief background to chapter $\mathrm{x}$;

- $\quad$ Chapter x: The USA is not covered;

- Zimbabwe is incorrectly regarded as central Africa. Pages xxx - xxx;

- China's role in the Cold War needs expansion; Vietnam and Mid East conflicts not covered;

- Heritage concerns 'constructed heritage icons', not heritage sites, as on pp. $\mathrm{x}$-xx (note misspelling of Mapungubwe, p.x).

In the History section, the bulk of comments focused on 5.1, source work. There were nine comments that concerned acknowledging the sources of illustrations, positive and negative, and six related to how topics were framed by key questions. Typical comments were:

- $\quad$ Sources are very well integrated into the text and the activities flow logically from them;

- Very good balance between sources and content and thorough engagement with sources is encouraged;

- Excellent range of sources. Various levels of questioning are employed;

- Use of multiple sources in activities most commendable - well referenced;

- Little attempt to find original and interesting photographs in many cases many heads of important people rather than sources to interact with;

- Not always clear what the purpose of the sources is throughout the book, as the activities do not consistently refer to them (e.g. 34 sources in Chapter $\mathrm{x}$ but only 13 referred to in activities);

- $\quad$ Some sources are not acknowledged and contextualised, e.g. pp.xxx - xxx;

- $\quad$ Source 13, p.xx, no caption or translation provided; p.xxx, no bubble text.

Sprinkled amongst the comments on content and sources were more general ones, such as:

- Text layout very plain and attempts to enrich it by boxes not consistently used in all chapters;

- The use of marginal icons, windows, boxes, etc. assists in highlighting important 
points;

- $\quad$ Only three cartoons in the book (all unacknowledged);

- Not many opportunities provided for enrichment/expansion.

\section{Applying selection criteria: Problems revealed by the 2007 process}

The 2007 textbook screening highlights many of the issues involved in textbook selection procedures. In retrospect, it was a saving grace that the process was labelled textbook "screening", rather than "selection", "assessment", or "evaluation", as it was certainly no more than that. It is also true that "screening" conveys that the formative function of the process was much more prominent than the summative, as few books were ultimately rejected on the second submission but all must have been improved in some way, albeit minimally in cases, as a result of what was a version of peer review.

Most significant amongst the concerns it raises is the (lack of) specification of a method for applying the criteria. Coltham (1970) was the only example found of a scheme that took the requirements for establishing compliance with the criteria as seriously as it took the criteria itself (though the Sparkling Waters colloquia did pay some attention to this aspect and published illustrations of good practice for some of the criteria (Siebörger, 1994b), and Stradling (2001) is at least cognisant of the need). The Department of Education's model provided no guidance at all for the interpretation of the criteria or for compiling the "strong" and "weak" points. It was, thus, impossible to ensure consistency of application and judgement at a level of detail. There is no evidence, however, to suggest that the final recommendations made to approve/conditionally approve/not approve were not deserved, based as they were on the scores awarded to each of the five sections. Ultimately much more disturbing is that there was no means to check or control that the assessments had been thoroughly done: Were the early chapters checked more carefully that the latter ones? How much of the content was carefully read? Was there more concern for checking references and spelling, than, e.g. the way sources were used in activities (which was only an implicit criterion)? Did the screeners devote more attention to pet criteria than to others? And so on.

The method of compiling the evaluation report is also open to question. There was no definition provided for what constituted "strong" or "weak" points other than that they were positive or negative, nor for any weighting of them. The request to provide a bulleted list rather than supporting paragraphs 
was obviously to save time, but it encouraged both a "list mentality" and the jotting down of fairly arbitrary, disconnected, points without proper justification for them. The result was that they made sense to the screeners but much less sense to the publishers and authors, to whom they were ultimately sent. Both the flavour of the report and the final score might likely have changed, had the instruction instead been to compile observations per section in paragraph style, rather than strong and weak points for the book as a whole.

If the criteria and their means of application are open to criticism, ought a place for history textbook selection to remain? This question is approached in the concluding section.

\section{The relationship of textbook selection to history education}

"Textbooks in Africa were found to fulfil three important purposes simultaneously: they provide the major vehicle for the curriculum; they are the main, if not only, source of information for the teacher; and examinations and student assessments are derived heavily from them" (Proctor \& Monteith, 1993:33 quoting a 1991 British Council report on textbook provision and library development). Despite the digital resources now available, this remains true of the situation in most schools in South Africa. Consequently, textbooks are centrally important to the practice of history education and their quality influences the quality of the history taught. Anything such as textbook screening and selection that may be used to strengthen and improve textbooks, is vitally important to history. History education should devote far more attention than hitherto to establishing and applying effective textbook selection criteria. In South Africa, the Sparkling Waters colloquia provided a unique opportunity to take this forward, but they were a decade too early and there is a severe risk that everything then hard fought for and achieved will be lost unless it is soon re-visited.

Tangentially, the 2007 textbook screening highlights the great benefit of having a selection of books for learners, teachers and examiners to use, as it clearly shows that there was no single book which was so much better than the others that it could in fact replace them. The books had a range of different strengths and weaknesses amongst them, not the least being that they reflected very well the diverse qualities of narrative, explanation, evidence and investigation that typify history as a discipline. To understand history at all there has to be more than one version available and more than one set of ideas 
with which to work. To that extent, one might find oneself looking back on 2007 as a golden moment for history education in South Africa, when there were 10 nationally approved and accessible textbooks available.

It is, therefore, an irony that it should be this very characteristic of history that may be its Achilles' heel regarding textbook selection. The multiple perspectives and approaches that are so valued can very easily translate into a laissez faire attitude of accepting any text or activities and a view that it is wrong to be prescriptive or judgemental about history textbooks as a whole. This case study shows, above all, that it is possible to develop better ways of assessing and selecting textbooks - and that it is possible to produce better textbooks. This must always remain the aim. Specification by means of criteria is desirable not for specification's sake but because it can create the opportunity to raise the standards of books.

In the ten years since the authors of the 2007 books first started writing their texts, much has changed in print and digital publishing. The growth of the internet and the enormous expansion of the resources available for history has meant, contrary to what one might have expected or hoped, that the quality of textbooks universally is dropping, resulting in shorter books that are compiled more quickly, using easily available material and largely ignoring pedagogy. History education needs urgently to benchmark what it is that is required to teach and study history, beyond TV series, YouTube and collections of visuals. The skill with which this can be done will be drawn from the body of academic work that has been devoted to textbook research, evaluation and selection, internationally and in South Africa, since 1945, as has been summarised well by Falk Pingel (2010). He reminds that "The textbook is just 'one medium in a chain of media'... Textbook revision cannot be restricted to the 'text', as the text itself is the result of a negotiated societal process" (2010:54).

\section{References}

Coltham, JB 1970. Assessing History books. Teaching History, No 3:213-218. Copy in Fines, J 1983. Teaching History. Edinburgh: Holmes McDougall.

Department of Education 2002. Revised national curriculum statement. Grades R-9. Overview. Pretoria: Department of Education. 
Department of Education 2003. National curriculum statement, Grades 10-12 (General): History. Pretoria: Department of Education.

Department of Education 2005. Subject assessment guidelines: History - September 2005. Pretoria: Department of Education.

Department of Education 2007. Guiding criteria for selecting textbooks. Pretoria: Department of Education. Unpublished.

Fetsko, W 1992. Approaching textbook selection systematically. In: JG Herlihy (ed.). The textbook controversy: Issues, aspects, perspective. Norwood: Ablex Publishing.

Havekes, PA, Luttenberg, J \& Van Boxtel, C 2012. Knowing and doing history: A conceptual framework and pedagogy for teaching historical contextualisation. International Journal of Historical Learning, Teaching and Research, 11(1):72-93.

Nichol, J \& Dean, J 2003. Writing for children: History textbooks and teaching texts. International Journal of Historical Learning, Teaching and Research, 3(2):53-82.

Nicholls, J 2003. Methods in school textbook research. International Journal of Historical Learning, Teaching and Research, 3(2):11-26.

Pingel, F 2010. UNESCO, Guidebook on Textbook Research and Textbook Revision, 2, first published 1999. UNESCO and Georg Eckert Institute: Paris and Braunschweig.

Proctor, A \& Monteith, M 1993. Textbooks, corruption and curricula. In: S Kromberg, M Govender, N Birrell \& M Sibanyoni (eds). Publishing for democratic education. Johannesburg: Sached.

SAQA 2001. Criteria and guidelines for the generation and evaluation of qualifications and standards within the National Qualifications Framework. Pretoria: South African Qualifications Authority.

Siebörger, R 1994a. Reconceptualising South African school History textbooks. South African Historical Journal 30, May:98-108.

Siebörger, R 1994b. New History textbooks for South Africa. Johannesburg: Macmillan.

Siebörger, R 1996. Selecting and evaluating school history textbooks. Joint conference of the South African Historical Association and the South African Society for History Teaching, University of Potchefstroom. Unpublished paper.

Siebörger, R 2006. The dynamics of History textbook production during South Africa's educational transformation. In: S Foster \& K Crawford (eds.). What shall we tell the children? International perspectives on school History textbooks. Greenwich: Information Age. 
Stradling, R 2001. Teaching 20th - century European history. Strasbourg: Council of Europe Publishing.

Wilkes, J 1977. Making the best use of textbooks. Teaching History, No 18:16-20. 